\title{
Preventive Effect of Preinduction of Metallothionein on Mutagenicity Caused by Benzo[a]pyrene
}

\author{
Masaki Takaishi, ${ }^{a}$ Junko S. Suzuki, ${ }^{b}$ Masahiko Satoh,,${ }^{a, c}$ and Hisamitsu Nagase ${ }^{*, a}$ \\ ${ }^{a}$ Laboratory of Hygienic Chemistry and Molecular Toxicology, Gifu Pharmaceutical University, 5-6-1, Mitahora-higashi, Gifu 502- \\ 8585, Japan, ${ }^{b}$ Research Center for Environmental Risk, National Institute for Environmental Studies, 16-2, Onogawa, Tsukuba, \\ Ibaraki 305-8506, Japan and ${ }^{c}$ Laboratory of Pharmaceutical Health Sciences, School of Pharmacy, Aichi Gakuin University, 1-100, \\ Kusumoto-cho, Chikusaku, Nagoya 464-8650, Japan
}

(Received October 1, 2009; Accepted October 19, 2009; Published online October 30, 2009)

\begin{abstract}
The effect of pretreatment with zinc (Zn) compounds on the mutagenicity of benzo $[a]$ pyrene $(\mathrm{B}[a] \mathrm{P})$ was investigated using metallothionein (MT)-I/II null mice. MT-I/II null mice and wild-type mice were subcutaneously administered $\mathrm{ZnSO}_{4}$ once a day for 2 days and gavaged $\mathrm{B}[a] \mathrm{P}$ at $24 \mathrm{hr}$ after the last injection of $\mathrm{ZnSO}_{4} . \mathrm{B}[a] \mathrm{P}$ induced micronucleus frequencies were reduced by $\mathrm{Zn}$ pretreatment in the wild-type mice but not in the MT-I/II null mice. Zn administration significantly increased the concentration of MT in the liver and bone marrow cells of wild-type mice, but the statuses of other cellular antioxidants, such as glutathione, catalase and superoxide dismutase, were unchanged. In addition, the activity of a major $\mathrm{B}[a] \mathrm{P}$ metabolic activation enzyme, cytochrome P450 1A, was unchanged by Zn treatment in both MT-I/II null mice and wild-type mice. These results suggest that $\mathrm{Zn}$ pretreatment protects against the mutagenicity of $\mathrm{B}[a] \mathrm{P}$ through the induction of MT synthesis. The amount of MT produced in animals may determine their sensitivity to $\mathrm{B}[a] \mathrm{P}$ exposure.
\end{abstract}

Key words — metallothionein, benzo[ $a]$ pyrene, zinc, micronucleated reticulocyte

\section{INTRODUCTION}

Metallothionein (MT) is a low-molecularweight protein in which cysteine residues comprise approximately $30 \%$ of the amino acids. It also has a high affinity for heavy metal ions such as zinc ( $\mathrm{Zn})$, copper, cadmium and mercury. ${ }^{1)}$ There are four isoforms of MT, and MT-I and MT-II, the major isoforms, are known to be involved in many physiological and pathophysiological processes, such as intracellular storage, transport and metabolism of heavy metals in order to regulate essential trace metal homeostasis and protect against heavy metal toxicity. ${ }^{2)}$ It has also been suggested that MT reacts with free radicals and alkylating agents. ${ }^{3,4)}$ The synthesis of MT is induced by various factors, such as metals, hormones, cytokines, stress and chemicals. $^{5)} \mathrm{Zn}$ is known to be an effective inducer of MT synthesis, and MT primarily binds to Zn under physiological conditions. ${ }^{6)}$

*To whom correspondence should be addressed: Laboratory of Hygienic Chemistry and Molecular Toxicology, Gifu Pharmaceutical University, 5-6-1, Mitahora-higashi, Gifu 502-8585, Japan. Tel.: +81-58-237-3931; Fax: +81-58-237-5979; E-mail: nagase@gifu-pu.ac.jp
Several studies have reported that pretreatment with $\mathrm{Zn}$ as an MT-inducer can depress the toxicities of cisplatin, adriamycin and cadmium. ${ }^{7,8)}$ Moreover, previous studies have shown that dietary $\mathrm{Zn}$ inhibits chemical carcinogenesis. ${ }^{9}{ }^{10)}$ In these studies, however, it was unclear whether MT pre-induced by $\mathrm{Zn}$ directly prevents these toxicities, including chemical carcinogenesis, because $\mathrm{Zn}$ does not exclusively induce MT.

Benzo $[a]$ pyrene $(\mathrm{B}[a] \mathrm{P})$ is one of the polycyclic aromatic hydrocarbons (PAHs) classified as carcinogenic to humans by International Agency for Research on Cancer (IARC). ${ }^{11)} \mathrm{B}[a] \mathrm{P}$ has been shown to induce gene mutations, chromosomal aberrations and other types of genotoxic effects in various species and tissues. ${ }^{12)}$ Most humans are more or less constantly exposed to $\mathrm{B}[a] \mathrm{P}$, mainly through tobacco smoke, diesel engine exhaust fumes, various types of processed foods, coaltar, creosotes and coke ovens. ${ }^{13)} \mathrm{B}[a] \mathrm{P}$ itself is chemically inert, and requires metabolic activation by cytochrome P450 (CYP) enzymes to exhibit carcinogenicity in animals and humans. ${ }^{14)} \mathrm{B}[a] \mathrm{P}$ is metabolized to 7,8-dihydroxy-9,10-epoxy-7,8,9,10tetrahydrobenzo $[a]$ pyrene (BPDE), the most car- 
cinogenic form of $\mathrm{B}[a] \mathrm{P}$, mainly by CYP1A1, $1 \mathrm{~A} 2$ and $1 \mathrm{~B} 1$, and binds to the exocyclic nitrogen of deoxyguanosine in DNA. ${ }^{15)}$ Moreover, during metabolic processes, $\mathrm{B}[a] \mathrm{P}$ also produces quinone derivatives, which easily generate reactive oxygen species (ROS) and oxidatively damage DNA. ${ }^{16}$ ) Our recent studies using MT-I/II null mice have shown that MT plays a protective role in $\mathrm{B}[a] \mathrm{P}$-induced DNA damage. ${ }^{17)}$ MT-I/II null mice, which are MT-I and MT-II double knockout mice, have been used to directly evaluate the biological mechanism involved.

In the present study using MT-I/II null mice and wild-type mice, we investigate the effect of preinduction of MT, using a Zn compound as an MT inducer, on micronuclei $(\mathrm{MN})$ caused by $\mathrm{B}[a] \mathrm{P}$. We also investigate the effect of $\mathrm{Zn}$ treatment on the amounts of MT and glutathione (GSH) produced and the activities of catalase, superoxide dismutase (SOD) and CYP1A in the liver and bone marrow cells of MT-I/II null mice and wild-type mice.

\section{MATERIALS AND METHODS}

Chemicals - B $[a] \mathrm{P}$ was purchased from Sigma Chemicals Co. (St. Louis, MO, U.S.A.). Zinc sulfate $\left(\mathrm{ZnSO}_{4}\right)$, trichloroacetic acid, 5,5'-dithiobis(2nitrobenzoic acid) (DTNB) and hydrogen peroxide $\left(\mathrm{H}_{2} \mathrm{O}_{2}\right)$ were purchased from Wako Pure Chemical Industries, Ltd. (Osaka, Japan). SOD Assay kit-WST was purchased from Dojindo (Kumamoto, Japan).

Animals — MT-I/II null mice were kindly provided by Dr. K. H. A. Choo (Murdoch Institute for Research into Birth Defects, Royal Children's Hospital, Melbourne, Australia) and were of a mixed genetic background of 129 Ola and C57BL/6 strains. ${ }^{18)}$ F1 hybrid mice were mated with C57BL/6J mice and their offspring were backcrossed to C57BL/6J for six generations. Both MTI/II null mice and wild-type mice were generated by mating of heterozygous mice.

MT-I/II null mice and wild-type mice were routinely bred in the vivarium of Gifu Pharmaceutical University. Both strains of mice were housed in cages in ventilated animal rooms with a controlled temperature of $24 \pm 2^{\circ} \mathrm{C}$, a relative humidity of $55 \pm 10 \%$ and a $12 \mathrm{hr}$ light/dark cycle. The mice were maintained on standard laboratory chow and tap water ad libitum, and received humane care throughout the experiment according to the guide- lines of Gifu Pharmaceutical University.

Treatments — Ten-week-old male MT-I/II null mice and wild-type mice were randomized into control and experimental groups (5 mice for each group). The groups of mice were subcutaneously administered $\mathrm{ZnSO}_{4}(100 \mu \mathrm{mol} / \mathrm{kg})$ once a day for 2 days and orally administered B $[a] \mathrm{P}(250 \mathrm{mg} / \mathrm{kg})$ once at $24 \mathrm{hr}$ after the last administration of $\mathrm{ZnSO}_{4}$. Peripheral blood was collected from the mouse tail vein under diethyl ether anesthesia at $48 \mathrm{hr}$ after the $\mathrm{B}[a] \mathrm{P}$ injection. In addition, the liver and bone marrow cells were removed from each mouse under diethyl ether anesthesia at $24 \mathrm{hr}$ after the last administration of $\mathrm{ZnSO}_{4}$.

MN Test — Peripheral blood smeared on glass slides (Matsunami Glass Industries, Osaka, Japan) was stained with acridine orange according to the method described by Hayashi et al. ${ }^{19)}$ For each animal, 1000 reticulocytes (RET) were scored for MN and the frequencies of micronucleated reticulocytes (MNRET) were expressed as a percentage of RET.

Measurement — MT (MT-I and MT-II isoforms) concentrations in the liver and bone marrow cells were measured by radioimmunoassay ${ }^{20)}$ as modified by Nishimura et al. ${ }^{21)}$ using sheep anti-rat MT-I antiserum. $10 \%$ liver homogenate was prepared in $10 \mathrm{mM}$ Tris-HCl. Protein was identified using BCA Protein Assay Kit (Thermo, Waltham, MA, U.S.A.) with bovine serum albumin as a standard.

GSH concentrations in the liver and bone marrow cells were measured by the method of Moron et $a l .{ }^{22)}$ The tissues were homogenized in phosphate bufferved saline (PBS) to obtain a final concentration of $10 \%$ homogenate. The rate of reduction of DTNB was recorded spectrophotometrically at a wavelength of $412 \mathrm{~nm}$. The GSH content was quantified by comparison with a standard curve generated with known amounts of GSH (reduced form) and expressed as $\mu \mathrm{mol}$ per mg protein.

For the measurement of catalase activity, we used the method of Aebi et al. ${ }^{23)}$ One unit of catalase activity is equal to the amount of enzyme required to convert $1 \mu \mathrm{mol}$ of $\mathrm{H}_{2} \mathrm{O}_{2}$ to oxygen and water in $1 \mathrm{~min}$, and the activity of catalase was expressed as units of catalase/ $\mu \mathrm{g}$ of protein.

The assay for SOD activity was measured using SOD Assay kit-WST according to the manufacturer's instructions. The tissues were homogenized in sucrose buffer to obtain a final concentration of $20 \%$ homogenate. One unit of SOD was defined as the enzyme activity causing $50 \%$ inhibition of the oxidation of water soluble tetrazolium salts (WST)- 
1 reduction rate. The activity of SOD was expressed as units of SOD/mg of protein.

For the measurement of CYP1A activity, 7ethoxyresorufin $O$-deethylation (EROD) activity in liver microsomes was determined by the method of Shimada et al. ${ }^{24)}$

Statistical Analysis — All values were expressed as the mean \pm S.D. Differences in the mean values were assessed by analysis of variance (ANOVA) followed by Newman-Keuls tests for post hoc comparison. Differences were considered statistically significant at $p<0.05$.

\section{RESULTS}

\section{MN Test}

The results of the MN test are shown in Fig. 1. No significant changes in $\mathrm{MN}$ production were found after treatment with $\mathrm{ZnSO}_{4}$. The frequencies of MNRET were significantly increased by the administration of $\mathrm{B}[a] \mathrm{P}$ in both the MT-I/II null mice and the wild-type mice; however, the frequency of MNRET in the MT-I/II null mice was significantly higher. Pretreatment with $\mathrm{ZnSO}_{4}$ significantly decreased the frequency of MNRET increased by $\mathrm{B}[a] \mathrm{P}$ in the wild-type mice but not in the MT-I/II null mice.

\section{MT Concentration}

MT concentrations were determined in the liver and bone marrow cells of MT-I/II null mice and wild-type mice at $24 \mathrm{hr}$ after the last injection of $\mathrm{ZnSO}_{4}$ (Table 1). In the wild-type mice, MT concentrations in the liver and bone marrow cells were increased by $\mathrm{ZnSO}_{4}$ administration to 14- and 2.7fold that of vehicle control mice, respectively. In contrast, MT concentrations in the liver and bone

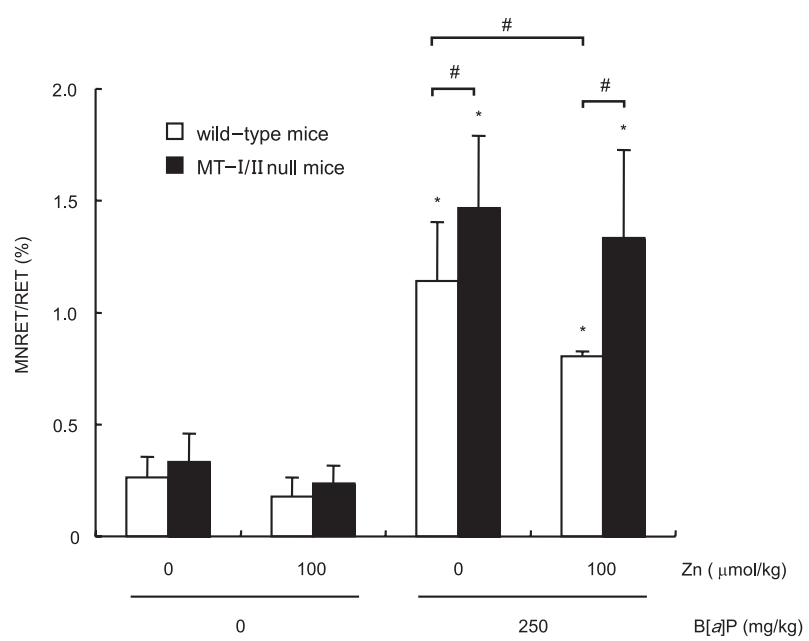

Fig. 1. Frequencies of MNRET in Peripheral Blood of MT-I/II Null Mice and Wild-type Mice Treated with $\mathrm{B}[a] \mathrm{P}$

Values are represented as mean \pm S.D. ${ }^{*}$ Statistically significant differences from the corresponding control group $(p<0.05)$. Statistically significant differences are indicated with ${ }^{\#} p<0.05$.

Table 1. Concentrations of MT and GSH, and Activities of Catalase and SOD in Liver (A) and Bone Marrow Cells (B) of MT-I/II Null Mice and Wild-type Mice Pretreated with $\mathrm{ZnSO}_{4}$

(A) Liver

\begin{tabular}{|c|c|c|c|c|}
\hline & \multicolumn{2}{|c|}{ wild-type mice } & \multicolumn{2}{|c|}{ MT-I/II null mice } \\
\hline & saline & $\mathrm{ZnSO}_{4}$ & saline & $\mathrm{ZnSO}_{4}$ \\
\hline MT & $5.48 \pm 2.75$ & $444.61 \pm 194.08^{*}$ & N.D. & N.D. \\
\hline GSH & $0.33 \pm 0.05$ & $0.31 \pm \quad 0.02$ & $0.37 \pm 0.04$ & $0.35 \pm 0.03$ \\
\hline catalase & $41.43 \pm 16.87$ & $43.44 \pm 7.59$ & $39.91 \pm 5.08$ & $42.50 \pm 5.66$ \\
\hline SOD & $128.99 \pm 13.71$ & $139.37 \pm 13.07$ & $129.37 \pm 9.01$ & $131.35 \pm 9.62$ \\
\hline
\end{tabular}

MT, $\mu \mathrm{g} / \mathrm{g}$ tissue; GSH, $\mu \mathrm{mol} / \mathrm{mg}$ protein; catalase, IU/ $\mu \mathrm{g}$ protein; SOD, U/mg protein. Values are means \pm S.D. Statistically significant differences from the control group. ${ }^{*} p<0.05$. N.D.: not detected. The limit of detection for the MT assay is $1.85 \mu \mathrm{g} / \mathrm{g}$ tissue.

(B) Bone marrow cells

\begin{tabular}{|c|c|c|c|c|}
\hline & \multicolumn{2}{|c|}{ wild-type mice } & \multicolumn{2}{|c|}{ MT-I/II null mice } \\
\hline & saline & $\mathrm{ZnSO}_{4}$ & saline & $\mathrm{ZnSO}_{4}$ \\
\hline MT & $68.48 \pm 9.90$ & $181.60 \pm 88.28^{*}$ & N.D. & N.D. \\
\hline GSH & $262.58 \pm 50.75$ & $320.25 \pm 92.64$ & $270.39 \pm 54.20$ & $266.52 \pm 57.1$ \\
\hline catalase & $89.13 \pm 11.95$ & $86.79 \pm 10.79$ & $82.05 \pm 15.23$ & $71.65 \pm 18.06$ \\
\hline SOD & $73.03 \pm 22.82$ & $69.52 \pm 26.09$ & $94.24 \pm 28.21$ & $65.70 \pm 11.85$ \\
\hline
\end{tabular}

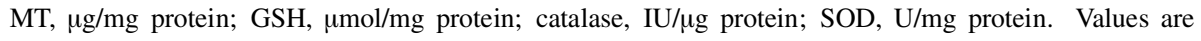
means \pm S.D. Statistically significant differences from the control group. ${ }^{*} p<0.05$. N.D.: not detected. The limit of detection for the MT assay is $50 \mu \mathrm{g} / \mathrm{mg}$ protein. 
Table 2. EROD Activities in the Liver and Bone Marrow Cells of MT-I/II Null Mice and Wild-type Mice Pretreated with $\mathrm{ZnSO}_{4}$

\begin{tabular}{lccccc}
\hline \hline & \multicolumn{2}{c}{ wild-type mice } & & \multicolumn{2}{c}{ MT-I/II null mice } \\
\cline { 2 - 3 } \cline { 5 - 6 } & saline & $\mathrm{ZnSO}_{4}$ & & saline & $\mathrm{ZnSO}_{4}$ \\
\hline liver & $7.25 \pm 1.00$ & $6.35 \pm 3.16$ & & $6.98 \pm 1.48$ & $7.54 \pm 3.93$ \\
bone marrow cells & N.D. & N.D. & & N.D. & N.D. \\
\hline
\end{tabular}

EROD, $\mathrm{nmol} / \mathrm{min}$ per $\mathrm{mg}$ protein. Values are means \pm S.D. N.D.: not detected.

marrow cells of MT-I/II null mice were below the limit of detection and were thus not induced by $\mathrm{ZnSO}_{4}$.

\section{GSH Concentration}

GSH levels in the liver and bone marrow cells of both MT-I/II null mice and wild-type mice administered $\mathrm{ZnSO}_{4}$ are shown in Table 1. No significant changes in GSH levels were observed between the $\mathrm{ZnSO}_{4}$ treatment group and the vehicle controls in the tissues of both MT-I/II null mice and wild-type mice.

\section{Antioxidant Enzymatic Activities}

Table 1 also shows the catalase and SOD activities in the liver and bone marrow cells of both MT-I/II null mice and wild-type mice administered $\mathrm{ZnSO}_{4}$. No significant changes in catalase and SOD activities were observed between the $\mathrm{ZnSO}_{4}$ treatment group and the vehicle controls in the tissues of both MT-I/II null mice and wild-type mice.

\section{CYP1A Enzymatic Activity}

Table 2 shows the EROD activities in the liver and bone marrow cells of both MT-I/II null mice and wild-type mice administered $\mathrm{ZnSO}_{4}$. Hepatic EROD activities were not changed between the $\mathrm{ZnSO}_{4}$ treatment group and the untreated control group of both MT-I/II null mice and wild-type mice. The EROD activities of bone marrow cells were not detected in either MT-I/II null mice or wild-type mice, and were thus considered not to be induced by $\mathrm{ZnSO}_{4}$ treatment.

\section{DISCUSSION}

We previously reported that MT-I/II null mice were more susceptible to $\mathrm{B}[a] \mathrm{P}$-induced chromosomal aberrations than wild-type mice. ${ }^{17}$ ) In the present study, $\mathrm{B}[a] \mathrm{P}$-induced $\mathrm{MN}$ frequency was reduced by $\mathrm{Zn}$ pretreatment in wild-type mice but not in MT-I/II null mice. Our results suggest that basal and metal-induced MT can play a protective role against the mutagenicity caused by $\mathrm{B}[a] \mathrm{P}$.

$\mathrm{B}[a] \mathrm{P}$ must be metabolically activated to exert its toxicity, and CYP-dependent metabolic activation appears to be required. Nagalingam et al. reported an in vitro study that showed that BPDE, the most important metabolite, forms DNA adducts to act as a mutagen. ${ }^{25)}$ CYP1A1, CYP1A2 and CYP1B1 have been shown to be the major enzymes in the metabolism of $\mathrm{B}[a] \mathrm{P}^{26)}$ Pathways for the activation of $\mathrm{B}[a] \mathrm{P}$ to its most carcinogenic metabolites by drug-metabolizing enzymes have extensively been studied. ${ }^{27)}$ Several researchers have demonstrated clearly that CYP1A1 is involved in the metabolic activation of $\mathrm{B}[a] \mathrm{P}$ into reactive intermediates capable of binding to DNA. ${ }^{26)}$ Numerous reports have shown that one or more of the reactive intermediates, rather than the nonmetabolized parent compound, is responsible for $\mathrm{B}[a] \mathrm{P}$-mediated mutations and carcinogenesis. ${ }^{12,28)}$ Expression of CYP1A1 is constitutively nil but is markedly induced in a large number of tissues after induction by PAHs. ${ }^{29)}$ In addition, constitutive CYP1B1 is extremely low in the liver but is detectable after PAH exposure. ${ }^{29)}$ In contrast, CYP1A2 is constitutively high in the mammalian liver. CYP1A1 and CYP1B1 are expressed in organs apart from the liver but CYP1A2 is mainly expressed in the liver. Our previous study showed that the oral administration of $\mathrm{B}[a] \mathrm{P}$ increased EROD activities in both MT-I/II null mice and wild-type mice, as a result of CYP1A activity. ${ }^{17)}$ In the present study, we measured EROD activities in the liver and bone marrow cells, and found that they were not changed between the $\mathrm{Zn}$ treatment group and the untreated control group in both MT-I/II null mice and wild-type mice. Thus, Zn pretreatment does not affect $\mathrm{B}[a] \mathrm{P}$ metabolic activation.

Metal compounds containing metals such as cadmium, Zn and bismuth can induce MT synthesis in vivo and in vitro. ${ }^{30)}$ Several investigators have reported that metal compounds induced MT to protect against the cytotoxicity and organ toxicity 
of various chemicals. ${ }^{31)}$ For example, pretreatment with bismuth compounds, as MT inducers, suppressed the $\mathrm{MN}$ induction by chromium compounds and selenium compounds. ${ }^{32)}$ Anticancer drugs, such as cisplatin, adriamycin, cyclophosphamide and Lphenylalanine mustard, induced $\mathrm{MN}$, but pretreatment with MT inducers could prevent this. ${ }^{33)} \mathrm{Re}-$ cently, a few reports have described using MT-I/II null mice to demonstrate that the protective effects of $\mathrm{Zn}$ pretreatment on cisplatin-induced renal toxicity and $\mathrm{X}$-irradiation-induced bone marrow injury were due to an induction of MT. ${ }^{34,35)}$ In the present study, Zn pretreatment suppressed the mutagenicity of $\mathrm{B}[a] \mathrm{P}$ in wild-type mice but not in MT-I/II null mice. These results clearly indicate, therefore, that the protective effect of $\mathrm{Zn}$ pretreatment on the mutagenicity of $\mathrm{B}[a] \mathrm{P}$ is also due to MT synthesis.

BPDE is well known to be the most effective carcinogen among the metabolites of $\mathrm{B}[a] \mathrm{P}$ in animals and human. ${ }^{15)}$ Moreover, $\mathrm{B}[a] \mathrm{P}$ produces various quinone derivatives and ROS, which are mutagenic and carcinogenic. ${ }^{36)} \mathrm{Zn}$ is known to induce the synthesis of MT through the activation of a metal-response elements that is located in the $5^{\prime}$ upstream region of the gene for MT. ${ }^{37)}$ Some researchers have proposed that MT efficiently eliminates ROS, and that the rate of reaction of MT with hydroxyl radicals is several hundred-fold higher than that of GSH. ${ }^{3)}$ Many studies have demonstrated that $\mathrm{Zn}$ supplementation provides effective protection against various oxidative injuries. ${ }^{6}$ Furthermore, the protective effect of MT against DNA damage caused by oxidative stress-inducing substances, such as hydrogen peroxide and cadmium, has been reported. ${ }^{38)}$ In the present study, Zn significantly increased the MT levels in hepatic and bone marrow cells without any effects on GSH levels or the activities of other cellular antioxidative enzymes such as catalase and SOD. Miura et al. reported that GSH levels and catalase and SOD activities in bone marrow cells were not affected by treatment with bismuth compounds. ${ }^{39)}$ Conrad et al. reported that neither the hepatic GSH levels nor catalase or SOD activities of Zn compound-treated MT-I/II null mice and wild-type mice were changed. ${ }^{40)}$ Our results in the present study suggest that $\mathrm{Zn}$-induced MT in bone marrow cells prevents $\mathrm{B}[a] \mathrm{P}$-induced oxidative DNA damage by scavenging free radicals.

Our previous report showed that MT-I/II null mice were more susceptible to $\mathrm{B}[a] \mathrm{P}$-induced DNA damage, without CYP1A activity being affected, compared with wild-type mice. ${ }^{17)}$ In the present study, Zn pretreatment increased MT synthesis in the liver, the major metabolic organ of $\mathrm{B}[a] \mathrm{P}$, and also in bone marrow cells that are $\mathrm{B}[a] \mathrm{P}$-caused $\mathrm{MN}$; however, other cellular antioxidants levels and metabolic activation of $\mathrm{B}[a] \mathrm{P}$ were unchanged.

In conclusion, we found that the $\mathrm{Zn}$ pretreatment effectively prevented the mutagenicity of $\mathrm{B}[a] \mathrm{P}$, and its effect was due to MT induced by $\mathrm{Zn}$. These results suggest that MT is a major preventive factor against the mutagenicity caused by $\mathrm{B}[a] \mathrm{P}$.

Acknowledgement The authors thank Dr. Chiharu Tohyama (The University of Tokyo, Tokyo, Japan) for providing the MT-I/II null mice.

\section{REFERENCES}

1) Kagi, J. H. and Schaffer, A. (1988) Biochemistry of metallothionein. Biochemistry, 27, 8509-8515.

2) Miles, A. T., Hawksworth, G. M., Beattie, J. H. and Rodilla, V. (2000) Induction, regulation, degradation, and biological significance of mammalian metallothioneins. Crit. Rev. Biochem. Mol. Biol., 35, 35-70.

3) Thornalley, P. J. and Vasak, M. (1985) Possible role for metallothionein in protection against radiationinduced oxidative stress. Kinetics and mechanism of its reaction with superoxide and hydroxyl radicals. Biochim. Biophys. Acta, 827, 36-44.

4) Endresen, L. and Rugstad, H. E. (1987) Protective function of metallothionein against certain anticancer agents. Experientia Suppl., 52, 595-602.

5) Cai, L., Satoh, M., Tohyama, C. and Cherian, M. G. (1999) Metallothionein in radiation exposure: its induction and protective role. Toxicology, 132, 8598.

6) Naganuma, A., Satoh, M., Koyama, Y. and Imura, N. (1985) Protective effect of metallothionein inducing metals on lethal toxicity of cisdiamminedichloroplatinum in mice. Toxicol. Lett., 24, 203-207.

7) Satoh, M., Cherian, M. G., Imura, N. and Shimizu, H. (1994) Modulation of resistance to anticancer drugs by inhibition of metallothionein synthesis. Cancer Res., 54, 5255-5257.

8) Conrad, C. C., Walter, C. A., Richardson, A., Hanes, M. A. and Grabowski, D. T. (1997) Cadmium toxicity and distribution in metallothionein-I and -II deficient transgenic mice. J. Toxicol. Environ. Health, 52, 527-543.

9) Poswillo, D. E. and Cohen, B. (1971) Inhibition 
of carcinogenesis by dietary zinc. Nature (London), 231, 447-448.

10) Duncan, J. R. and Dreosti, I. E. (1975) Zinc intake, neoplastic DNA synthesis, and chemical carcinogenesis in rats and mice. J. Natl. Cancer Inst., 55, 195-196.

11) IARC working group on the evaluation of carcinogenic risks to humans (in preparation) Air pollution, Part 1, some non-heterocyclic polycyclic aromatic hydrocarbons and some related industrial exposure. IARC Monogr. Eval. Carcinog. Risks Hum., 92, in preparation.

12) Conney, A. H., Chang, R. L., Jerina, D. M. and Wei, S. J. (1994) Studies on the metabolism of benzo[a]pyrene and dose-dependent differences in the mutagenic profile of its ultimate carcinogenic metabolite. Drug Metab. Rev., 26, 125-163.

13) Hattemer-Frey, H. A. and Travis, C. C. (1991) Benzo-a-pyrene:environmental partitioning and human exposure. Toxicol. Ind. Health, 7, 141-157.

14) Conney, A. H. (1982) Inducion of microsomal enzymes by foreign chemicals and carcinogenesis by polycyclic aromatic hydrocarbons: G. H. A. Clowes Memorial Lecture. Cancer Res., 42, 4875-4917.

15) Weinstein, I. B., Jeffrey, A. M., Jennette, K. W., Blobstein, S. H., Harvey, R. G., Harris, C., Autrup, H., Kasai, H. and Nakanishi, K. (1976) Benzo(a)pyrene diol epoxides as intermediates in nucleic acid binding in vitro and in vivo. Science, 193, 592-595.

16) Penning, T. M., Ohnishi, S. T., Ohnishi, T. and Harvey, R. G. (1996) Generation of reactive oxygen species during the enzymatic oxidation of polycyclic aromatic hydrocarbon trans-dihydrodiols catalyzed by dihydrodiol dehydrogenase. Chem. Res. Toxicol., 9, 84-92.

17) Takaishi, M., Sawada, M., Shimada, A., Suzuki, J. S., Satoh, M. and Nagase, H. (2009) Protective role of metallothionein in benzo[ $a]$ pyrene-induced DNA damage. J. Toxicol. Sci., 34, 449-458.

18) Michalska, A. E. and Choo, K. H. (1993) Targeting and germ-line transmission of a null mutation at the metallothionein I and II loci in mouse. Proc. Natl. Acad. Sci. U.S.A., 90, 8088-8092.

19) Hayashi, M., Morita, T., Kodama, Y., Sofuni, T. and Ishidate, M., Jr. (1990) The micronucleus assay with mouse peripheral blood reticulocytes using acridine orange-coated slides. Mutat. Res., 245, 245-249.

20) Tohyama, C. and Shaikh, Z. A. (1981) Metallothionein in plasma and urine of cadmium-exposed rats determined by a single-antibody radioimmunoassay. Fundam. Appl. Toxicol., 1, 1-7.

21) Nishimura, H., Nishimura, N. and Tohyama, C.
(1990) Localization of metallothionein in the genital organs of the male rat. J. Histochem. Cytochem., 38, 927-933.

22) Moron, M. S., Depierre, J. W. and Mannervik, B. (1979) Levels of glutathione, glutathione reductase and glutathione S-transferase activities in rat lung and liver. Biochim. Biophys. Acta, 582, 67-78.

23) Aebi, H. (1984) Catalase in vitro. Methods Enzymol., 105, 121-126.

24) Shimada, T., Wunsch, R. M., Hanna, I. H., Sutter, T. R., Guengerich, F. P. and Gillam, E. M. (1998) Recombinant human cytochrome P450 1B1 expression in Escherichia coli. Arch. Biochem. Biophys., 357, 111-120.

25) Nagalingam, A., Seo, K. Y. and Loechler, E. L. (2005) Mutagenesis studies of the major benzo $[a]$ pyrene $N^{2}$-dG adduct in a $5^{\prime}$-TG versus a $5^{\prime}$-UG sequence: removal of the methyl group causes a modest decrease in the $[\mathrm{G} \rightarrow \mathrm{T} / \mathrm{G} \rightarrow \mathrm{A}] \mathrm{mu}-$ tational ratio. Mutagenesis, 20, 105-110.

26) Shimada, T., Hayes, C. L., Yamazaki, H., Amin, S., Hecht, S. S., Guengerich, F. P. and Sutter, T. R. (1996) Activation of chemically diverse procarcinogens by human cytochrome P-450 1B1. Cancer Res., 56, 2979-2984.

27) Wood, A. W., Levin, W., Lu, A. Y., Yagi, H., Hernandez, O., Jerina, D. M. and Conney, A. H. (1976) Metabolism of benzo[a]pyrene and benzo $[a]$ pyrene derivatives to mutageneic products by highly purified hepatic microsomal enzymes. $J$. Biol. Chem., 251, 4882-4890.

28) Pelkonen, O. and Nebert, D. W. (1982) Metabolism of polycyclic aromatic hydrocarbons: etiologic role in carcinogenesis. Pharmacol. Rev., 34, 189-222.

29) Shimada, T., Inoue, K., Suzuki, Y., Kawai, T., Azuma, E., Nakajima, T., Shindo, M., Kurose, K., Sugie, A., Yamagishi, Y., Fujii-Kuriyama, Y. and Hashimoto, M. (2002) Arylhydrocarbon receptordependent induction of liver and lung cytochromes P450 1A1, 1A2, and 1B1 by polycyclic aromatic hydrocarbons and polychlorinated biphenyls in genetically engineered C57BL/6J mice. Carcinogenesis, 23, 1199-1207.

30) Durnam, D. M. and Palmiter, R. D. (1984) Induction of metallothionein-I mRNA in cultured cells by heavy metals and iodoacetate: evidence for gratuitous inducers. Mol. Cell. Biol., 4, 484-491.

31) Satoh, M., Kondo, Y., Mita, M., Nakagawa, I., Naganuma, A. and Imura, N. (1993) Prevention of carcinogenicity of anticancer drugs by metallothionein induction. Cancer Res., 53, 4767-4768.

32) Itoh, S. and Shimada, H. (1996) Micronucleus induction by chromium and selenium, and suppression 
by metallothionein inducer. Mutat. Res., 367, 233236.

33) Nakagawa, I., Nishi, E., Naganuma, A. and Imura, N. (1995) Effect of preinduction of metallothionein synthesis on clastogenicity of anticancer drugs in mice. Mutat. Res., 348, 37-43.

34) Satoh, M., Aoki, Y. and Tohyama, C. (1997) Protective role of metallothionein in renal toxicity of cisplatinum. Cancer Chemother. Pharmacol., 40, 358362.

35) Shibuya, K., Suzuki, J. S., Kito, H., Naganuma, A., Tohyama, C. and Satoh, M. (2008) Protective role of metallothionein in bone marrow injury caused by X-irradiation. J. Toxicol. Sci., 33, 479-484.

36) Sullivan, P. D. (1985) Free radicals of benzo(a)pyrene and derivatives. Environ. Health Perspect., 64, 283-295.

37) Palmiter, R. D. (1994) Regulation of metalloth- ionein genes by heavy metals appears to be mediated by a zinc-sensitive inhibitor that interacts with a constitutively active transcription factor, MTF-1. Proc. Natl. Acad. Sci. U.S.A., 91, 1219-1223.

38) Chubatsu, L. S. and Meneghini, R. (1993) Metallothionein protects DNA from oxidative damage. Biochem. J., 291, 193-198.

39) Miura, N., Satoh, M., Imura, N. and Naganuma, A. (1998) Protective effect of bismuth nitrate against injury to the bone marrow by $\gamma$-irradiation in mice: possible involvement of induction of metallothionein synthesis. J. Pharmacol. Exp. Ther, 286, 1427-1430.

40) Conrad, C. C., Grabowski, D. T., Walter, C. A., Sabia, M. and Richardson, A. (2000) Using MT(-/-) mice to study metallothionein and oxidative stress. Free Radic. Biol. Med., 28, 447-462. 